Artigos

\title{
Corpos em situaç̦ão de rua: entre práticas de normalização e resistência
}

\author{
Daiane Gasparetto da Silva
}

Flávia Cristina Silveira Lemos²

Dolores Galindo ${ }^{3}$

Resumo Considerando os fluxos, idas e vindas a determinadas condições de vida, busca-se pensar a produção de desigualdade social e econômica no intuito de trazer à análise os pormenores das relações de força dinâmicas que possibilitam o rompimento de vínculos, os quais estavam aparentemente estabilizados. Algumas situações são experimentadas como rupturas completamente estanques, desvinculadas de um contexto móvel que permite reconfigurações. Por fim, embora alguns sujeitos em vias de desfiliação possam ter em suas histórias certo modo de existir singular, em cada acontecimento é possível verificar que alguns sujeitos são conduzidos para fora do circuito de determinadas relações sociais de exclusão.

1 Doutoranda do Programa de Pós-Graduação em Psicologia /Universidade Federal do Pará (UFPA) Belém - Brasil - dai_gasp@hotmail.com

2 Professora do Programa de Pós-Graduação em Psicologia/UFPA. Bolsista de produtividade em pesquisa CNPQ-PQ2 - Belém - Brasil - flaviacslemos@gmail.com

3 Professora de Psicologia Social da Universidade federal do mato Grosso (UFMT) - Cuiabá - Brasil - dolorescristinagomesgalindo@gmail.com 
Palavras-chave: Pessoas em situação de rua; Psicologia Social; Sociologia; Singularidade; Desigualdades.

\section{Bodies in the streets: between standardization practices and resistance}

Abstract Considering the flows back and forth to certain conditions of life, we try to reflect on the production of social and economic inequality in order to bring to analysis the details of the dynamic power relations that enable the breaking of bonds, which were apparently stabilized. Some situations are experienced as completely watertight breaks, disconnected from a mobile context that allows reconfigurations. Finally, although some subjects in disaffiliation routes may have in their unique way of certain stories exist in every event we can see that some subjects are conducted out of the circuit of certain social relations of exclusion.

Keywords: People on the streets; Social Psychology; sociology; uniqueness; Inequalities.

\section{Introdução}

$\mathrm{O}$ artigo tem um formato de ensaio, abordando alguns conceitos e aspectos dos processos de desfiliação social de pessoas em situação de rua, os quais foram trabalhados em parte de uma pesquisa de mestrado com continuidade no doutorado. A metodologia transitou entre aportes de Deleuze, Foucault, Castel e Guattari, tanto na analítica de documentos quanto na criação de arquivos por meio de conversas com a arqueologia dos saberes, a genealogia dos poderes e a cartografia dos processos de subjetivação nos entremeios das práticas de existência das pessoas em situação de rua, em Belém do Pará.

Todavia, esse artigo é um recorte de diagramas dos fluxos das idas e vindas, realizados em determinadas condições específicas dos percursos da pesquisa, no que tange à busca do pensar a produção de desigualdade social e econômica, no intuito de trazer à análise alguns pormenores das relações de força dinâmicas que possibilitam o rompimento de vínculos, os quais estavam aparentemente estabilizados e cristalizados. Algumas situações de vida nas ruas são experimentadas como rupturas completamente estanques, desvinculadas de um contexto móvel que permite reconfigurações existenciais.

Há, ao longo do texto, uma aposta na postura ética, estética e política de não homogeneizar o conceito de exclusão e, muito menos, generalizá-lo para as pessoas, às quais estão situadas na periferia da sociedade, não em sentido restritamente espacial, mas também em termos de acesso aos direitos básicos. 
Comumente desligados da esfera do trabalho e, consequentemente, de fontes de renda estáveis, estão sujeitos à precarização da alimentação, da saúde, dos cuidados com o corpo. Mas há também aqueles que mantêm determinados padrões de vida, mesmo estando em rumos de desfiliação, o que demonstra a complexidade na discussão sobre o tema, posto que, em alguns casos, as fronteiras entre o que faz ser considerado ou não um desfiliado são muito tênues.

Segundo Castel (1997), quando tudo é colocado em um mesmo patamar denominado "exclusão", as estratégias de reparo, quer dizer, de inserção social, são privilegiadas ao invés daquelas que visam prevenir, atenuando os fatores que propiciam certo desequilíbrio social. Para o autor, as pessoas, antes de serem visadas como excluídas por intervenções especializadas, precisariam ser consideradas como capazes de produzir, implicando, então, ações de estímulo à sua vinculação às redes da sociedade. Por essa razão, as mudanças no que tange à "exclusão" não se dariam por meio de atividades reparadoras, porém, por meio da adoção de novas medidas que possibilitassem o tratamento social do desemprego e até mesmo a inserção de indivíduos vistos como inválidos em decorrência das condições socioeconômicas.

Em alguns casos, quando, por exemplo, parte da população é discriminada explicitamente, Castel (1997) destaca haver exclusão propriamente dita, mas sendo raras no presente as situações de exclusões radicais que desvinculam os sujeitos por completo dos grupos sociais. Já na visão de Passetti (2005), a sociedade contemporânea, que pode ser caracterizada como sociedade de controle, prevê o abarcamento de todos nas políticas instituídas, mesmo que seja pela via de inclusões excludentes, as quais podem ceder espaços para os sujeitos em categorizações de desqualificação.

Entre os diversos grupos que podem ser vistos pelo viés da desfiliação estão aqueles nomeados de imprestáveis: os denominados vagabundos que destoam de uma conjuntura social (CASTEL, 2010), mantida por uma rede cujos pontos deveriam se ligar para a manutenção de uma esperada coesão. A elaboração do discurso que atrela esse segmento à noção de infâmia aponta para efeitos que se veem difusos na sociedade como um todo, propagando preconceitos frente a um cenário capitalista, o qual desprivilegia os que estão fora dos padrões de consumo em lógica empresarial das relações. Castel (2010), ao fazer um apanhado histórico sobre os vagabundos - que tende às vezes mais ao contexto francês e europeu -, auxilia na reflexão das estratégias de afastamento desses sujeitos cujos traços podem estar reatualizados no presente, em diferentes regiões do globo. 
Segundo o autor, no século XVI, a estigmatização desse grupo populacional infame caracterizava-o como ocioso por não trabalhar (sequer com a terra, para garantir seu sustento), sendo também visto como desprovido de fé e lei. De acordo com essa lógica, a ausência de emprego e recursos, assim como de vinculação a uma comunidade determinariam a condição de vagabundagem. Lançados à sorte dos que "não têm raízes", dos que perambulam fazendo de qualquer lugar sua morada, sua "inutilidade" aparecia vinculada à noção do parasita que depende de outros para existir.

No Antigo Regime, com o intuito de distanciá-los dos principais centros, muitos foram banidos, deixados à revelia, vagando sem destino. Todavia, por esse procedimento ser avaliado como uma alternativa sem eficiência - já que os "indesejados" apenas eram deslocados -, logo passou a ser desprezado. Condená-los à morte e às galeras (a fim de serem capturados para sua utilização como mão de obra), deportá-los para as colônias ou sujeitá-los a trabalhos em reclusões e depósitos foram outras medidas adotadas em nome da ordem social, mas igualmente sem sucesso, o que as levou a ser abandonadas depois de tantas mortes.

Interessante pensar que, por mais que na atualidade a condenação à morte não seja mais usada como meio formal de extinção do "problema dos vagabundos", ainda há hoje parcela da sociedade que usa esses artifícios para se ver livre desses sujeitos, tal como se observa nas ocorrências que envolvem assassinatos de pessoas em situação de rua, em centros urbanos do Brasil. O deslocamento forçado dessa população para outras localidades é igualmente notado em casos pontuais, o que ficou claro, por exemplo, nas ações higienistas em algumas cidades, durante a Copa do Mundo de 2014, no Brasil. E, embora as instituições asilares mencionadas por Castel não sejam exatamente as mesmas da atualidade, a lógica reaparece materializando-se na diferença, na produção de novos depositários de corpos vagabundos os quais se erguem sob a demanda da proteção.

$\mathrm{Na}$ opinião de Castel (2010), por estar o dito vagabundo, em muitos casos, imerso em condições ultrajantes, a transgressão da lei aparece para si como uma possibilidade de obtenção de algo que precisa ou almeja. No entanto, apesar de não ser uma regra envolver-se em infrações, ele acaba por ter sua aparência conectada a daquelas pessoas cujas condutas são consideradas como potencialmente criminosas. Acerca desse paradigma negativo do vagabundo, o autor enfatiza que o mesmo é um discurso do poder, o qual pode ser usado por gestores sociais em ações repressivas que visem, no mínimo, a formas provisórias de lidar com os efeitos de uma situação complexa de desigualdade. A partir das proposições de Castel, a reflexão é enriquecida quando não tomada pelo simples viés da falta, mas de todos os elementos que 
compõem as trajetórias de vida, da desfiliação que passa pelas perdas e pela configuração de outras redes de inventividade em busca de estilísticas de existir no espaço dos entremeios.

\section{Processos de subjetivação na cidade}

A presença de pessoas em processo de desfiliação social, em contextos urbanos inquieta uma grande parcela da população e os órgãos governamentais, uma vez que ela produz inúmeras situações adversas à esperada ordem social. Nas cidades, o número crescente de pessoas em situação de rua agrava essa problemática e expõe violações de direitos evidenciadas nas condições precárias de vida.

Em função de o modo particular de viver nas ruas propiciar inúmeras problematizações pertinentes à análise do funcionamento da sociedade, torna-se cada vez mais importante estudar o trajeto para a rua (assim como aquele que se dá em sua permanência nela) como forma de entender as ramificações da questão. Para Frangella (2004), a trajetória de pessoas em situação de rua envolve uma história gradual de perdas e desvinculações, tendo como ponto de chegada a rua e, consequentemente, um tipo de esvaziamento territorial e identitário anterior. Em muitos momentos, essas pessoas, antes de se encontrarem na situação-limite de estar nas ruas, já passaram por um processo de ampla circulação por inúmeros circuitos, o que se observa em casos de indivíduos que rompem com as conexões familiares, passam por vários trabalhos, mas que voltam das ruas para casa. Segundo a autora, o trânsito de crianças e adolescentes, por exemplo, acontece de forma diferente, posto que os recursos e as perspectivas para saída da rua são maiores para os jovens do que para os adultos.

Ao longo dessas trajetórias de desfiliação, são vistos processos de subjetivação específicos, os quais, segundo Deleuze (1992), dizem respeito à produção de modos de existências, podendo estes ser considerados tanto éticos quanto estéticos. Já em uma perspectiva com Foucault, Castro (2009) ressalta que os modos de subjetivação são relativos às práticas que constituem os sujeitos, as quais podem ser compreendidas de dois modos, com base na análise realizada por Revel (2011): 1) práticas de objetivação e 2) constituição do ser humano por meio de um conjunto de técnicas de si. De acordo com Rodrigues e Baptista (2010), as modificações realizadas nas cidades ao longo da história não se restringiram ao âmbito físico-espacial, uma vez que elas se mostraram profundamente relacionadas às alterações nos modos de existência, no interior do campo da subjetividade. Nessa direção, os autores propõem: 
[...] adentrar as questões que concernem às articulações entre subjetividade e espaço através de sua tessitura co-constitutiva, e não de modificações que se abatem sobre duas realidades epistemológica e ontologicamente distintas. Em outras palavras, propomos uma análise dos processos que narram as tramas e embates que constituem o indivíduo - enquanto suporte hegemônico da experiência moderna - e o espaço ordenado e racional das grandes cidades. (Rodrigues \& Baptista, 2010: 423).

É no espaço onde ocorrem os embates e se engendram as estratégias e táticas, o que não confere à relação entre subjetividade e lugar um caráter de unificação e ausência de história. Pelas noções mencionadas e considerando as diversas forças que cruzam os indivíduos, ao longo de seus percursos na cidade, vale a pena pensar nos aspectos específicos que auxiliam na consolidação de modos de existência nas ruas, os quais se contrapõem ao que Lemos, Chaves e Prado Filho (2012) chamam de mundo privado e intimista, associado aos novos modos de objetivação e subjetivação na modernidade.

De acordo com os estudos de Frangella (2004), a vinculação aos espaços urbanos por parte de indivíduos em situação de rua inclui também processos adaptativos, os quais são notabilizados pelas alternativas de sobrevivência encontradas e pelas formas de sociabilidade possibilitadas pela situação de rua. Nesse sentido, são tidas como elementos importantes as amizades construídas nesse contexto, além das pessoas e instituições que auxiliam prestando assistência. Um dos aspectos da dinâmica dessa população é marcado pelo deslocamento nômade, o qual é ocasionado pela busca de recursos e pela contínua expulsão de lugares usados para descanso.

Nessa direção, observa-se que existem diferentes intensidades de circulação, as quais variam de acordo com os níveis de ajuste desses indivíduos ao espaço urbano. E é a partir dessas intensidades de movimento errante e das distintas experiências urbanas que são criadas as redes territoriais de circulação desses indivíduos. Em meio a esse percurso itinerante, as pessoas em situação de rua, frequentemente, buscam por espaços não utilizados, podendo também apropriar-se temporariamente de locais destinados à passagem de pessoas e carros, ou seja, espaços públicos de circulação.

Nota-se, assim, que as práticas sociais de pessoas em situação de rua são marcadas por essa circulação constante, o que propicia, por exemplo, trabalhos peculiares a esses contextos, como os serviços temporários. Nas alternativas de sobrevivência utilizadas por essa população, encontram-se também a mendicância, a vigilância de carros, a prostituição, o roubo, "opções" (ou "imposições”) que, fora da esfera do prestígio social, contribuem ainda mais para diferentes tipos de estigmatização da pobreza. 
Nesse processo de experimentação da cidade, tendo em vista a condição de estar nas ruas, os caminhos percorridos estão igualmente aliados a um caráter ético, relativo ao modo de se conduzir. Por isso, é preciso tentar entender de que forma são construídas tais rotas, a fim de entrar em contato com os aspectos de invenção de vidas expostas que testemunham sobre uma determinada história local e contribuem a seu modo para a afirmação de uma política da existência.

\section{Resistências como campos de possiveis}

As violações de direitos sociais estão presentes em todas as cidades, o que pode ser visto em várias situações do cotidiano. Os frequentes casos de extermínio de pessoas em situação de rua, remoção de famílias pobres que habitam espaços de especulação imobiliária, entre outros exemplos, apenas sublinham um cenário marcado por interesses que segregam grupos, principalmente em função de aspectos econômicos. Na realidade contemporânea, as pessoas em situação de rua chamam bastante atenção em espaços públicos, por transformá-los em áreas de intensa utilização. Por diversas vezes, seus corpos ficam camuflados nas calçadas, confundindo-se com a sujeira impressa nos pavimentos cobertos por cimento. Nesse sentido, seus corpos, marcados por aspectos da desigualdade social, acabam transformando-se em extensões do espaço, à medida que, para muitos, sequer são vistos como pessoas, porém, como empecilhos à manutenção da boa ordem social.

No intuito de problematizar, a partir de registros corporais, o processo de desfiliação social de indivíduos que se encontram nas ruas, é relevante sublinhar alguns aspectos gerais acerca da relação entre corpo e espaço urbano, para pensar a questão do testemunho corporal que se dá frente à violação de direitos. Por tal razão, na sequência, serão apresentadas algumas noções que ajudam a compor a reflexão sobre esse assunto. $\mathrm{O}$ funcionamento incessante das cidades abarca os corpos, fazendo-os trabalhar, na maior parte do tempo, sob a mesma lógica da aceleração dos automóveis e das demandas de produção. Assim, o espaço urbano, imbuído por valores socioculturais, revela-se como um lugar de acolhimento e repulsa aos indivíduos que por ele transitam. Assinala Bauman (2009: 35):

É nos lugares que se forma a experiência humana, que ela se acumula, é compartilhada, e que seu sentido é elaborado, assimilado e negociado. E é nos lugares, e graças aos lugares, que os desejos se desenvolvem, ganham forma, alimentados pela esperança de realizar-se, e correm risco de decepção - e, a bem da verdade, acabam decepcionados, na maioria das vezes. 
Com base nessa ideia e na noção de que a corporeidade humana se constrói com as vivências, pode-se sustentar que o espaço participa de modo único na configuração corporal de seus habitantes, principalmente pelas particularidades que o compõem. Os indivíduos agem por meio de gestos e movimentos, que são considerados como técnicas corporais constituídas por meio da cultura. Dessa forma, há em cada grupo social um modo específico de uso do corpo, o qual está atrelado ao contexto no qual os indivíduos se encontram. Nesse sentido, há de se considerar também as questões de adequação e adaptação culturais impostas ao sujeito, que o levam a desenvolver novas formas de expressão corporal em relação ao meio. Ao pensar o corpo pelo filtro dessas perspectivas, é possível traçar inúmeras relações entre os vários elementos presentes no espaço que, em contato com a esfera corporal, criam novas linhas de entendimento. Nesse sentido, Mendes (2010: 115) propõe a reflexão sobre o corpo com base no conceito de rizoma, destacando que:

[...] o corpo, assim como o rizoma, conecta-se a outros corpos e também ao meio, assim como destaca-se pelo caráter de heterogeneidade entre os corpos. Como o rizoma, o corpo também se caracteriza pela multiplicidade de informações nele impressas, bem como de outros corpos e, consequentemente, de caminhos por onde essas informações entram e saem. Assim como a individualidade de um sujeito se constrói na experiência da coletividade, conforme argumentado anteriormente, a unidade de um rizoma se dá a partir da multiplicidade. Como em um rizoma, em que qualquer ruptura pode vir a gerar uma nova linha, no corpo a apreensão ou aprendizagem de qualquer informação pode gerar novos percursos em busca de outras informações a receber ou a transmitir. Neste fluxo de agenciamentos, são constantes as desterritorializações e reterritorializações do corpo.

Em virtude de o rizoma estar sempre no espaço do entre, tanto na superfície quanto na profundidade, sua configuração não permite localizar o início e o fim de suas linhas. Ele pode ser caracterizado por seis princípios: 1) conexão; 2) heterogeneidade; 3) multiplicidade; 4) ruptura a-significante; 5) cartografia; 6) decalcomania (Deleuze; Guattari, 1995a).

$\mathrm{O}$ princípio de conexão diz respeito à possibilidade de qualquer ponto do rizoma se conectar a outros pontos. A heterogeneidade aponta para o fato de não haver obrigatoriedade de um determinado traço do rizoma fazer referência a outro semelhante. O princípio da multiplicidade diz que "[...] uma multiplicidade não tem nem sujeito nem objeto, mas somente determinações, grandezas, 
dimensões que não podem crescer sem que mude de natureza (as leis de combinação crescem então com a multiplicidade)" (Deleuze; Guattari, 1995a: 16). Dessa maneira, compreende-se que as multiplicidades são definidas pelas linhas abstratas, de fuga ou de desterritorialização, as quais mudam de natureza ao estabelecerem conexão com outras. Já o princípio da ruptura a-significante mostra que no rizoma sempre poderá haver rompimentos, os quais provocam a criação de linhas de fuga, ocasionando uma nova reconfiguração rizomática. Quanto ao princípio de cartografia e decalcomania, os autores ressaltam que não se pode tomar um rizoma a partir de um modelo estrutural ou gerativo, sendo necessário, portanto, que o rizoma seja visto da perspectiva do mapa e não do decalque. Desse modo, propõe-se a ideia de que o rizoma, enquanto mapa, favorece a conexão entre os pontos, posto que

[...] o mapa é aberto, é conectável em todas as suas dimensões, desmontável, reversível, suscetível de receber modificações constantemente. Ele pode ser rasgado, revertido, adaptar-se a montagens de qualquer natureza, ser preparado por um indivíduo, um grupo, uma formação social. (Deleuze; Guattari, 1995a: 22).

Com base nessa noção, é necessário tomar cuidado com o decalque, uma vez que ele estruturaliza o rizoma, organizando, estabilizando e neutralizando as multiplicidades de acordo com os seus eixos de significância e de subjetivação. Tomando como referenciais os princípios apresentados, os corpos dispostos no espaço da cidade podem ser vistos como um conjunto de linhas que se configura pela lógica do rizoma, o que propicia a existência de linhas duras, fluidas, bem como as de fuga, as quais se conectam em meio às forças que ligam o sujeito aos acontecimentos.

Para Jacques (2008), as linhas de fuga são aquelas de caráter micropolítico, que produzem resistência diante do que se impõe como modelo aceitável para a sociedade. Nesse sentido, no dia a dia, os sujeitos em contato com fatores sociais, culturais, econômicos, entre outros, podem agenciar mudanças em si. Por essa perspectiva, a corporeidade dos indivíduos está estreitamente regada por esses aspectos da relação do corpo com das multiplicidades proporcionadas pelo espaço. Segundo Paola Berenstein Jacques (2008), a escrita da cidade no corpo (e vice-versa), chamada de corpografia, pode ser estudada pelos padrões corporais de ação, que são os gestos e movimentos propiciados pela experiência urbana (Jacques, 2008). Com base nesse princípio, é possível pensar, fundamentado na corpografia urbana, o processo de ocupação dos espaços públicos 
e o modo como as forças, presentes nestes lugares estão relacionadas às vidas dos transeuntes. Os agenciamentos e escritas corporais propiciam uma experimentação mais intensa do espaço e de seus efeitos e as pessoas em situação de rua podem ser consideradas como deslocadas das regras temporais e sociais, beirando quase uma situação de refugiadas urbanas.

Ao lado dessa ideia, para Jacques (2008), as errâncias podem favorecer este outro tipo de velocidade no cotidiano, já que elas desviam rotas e desfazem roteiros, contribuindo para as rupturas a-significantes (Deleuze; Guattari, 1995a). Ao entregar-se à errância, o sujeito pode se perder, desorientando-se mesmo diante dos projetos urbanísticos que prezam pela condução. Suas atitudes podem ser lentas, no sentido de ignorar a lógica de celeridade do dia a dia, e seu corpo pode ser tomado pela materialização das reverberações de seus atos errantes (Jacques, 2008).

Importante ressaltar, com Deleuze e Guattari (1995a), que a lentidão não corresponde à aceleração ou retardação do movimento, mas à racionalidade do tipo de movimento, ou seja, que está presente no âmbito das condutas. $\mathrm{O}$ testemunho, conforme Agamben (2008), que por uma via tem valor de prova, pode também ser visto como o que compõe o testemunho daquele que não tem meios para testemunhar, o que indica o seu aspecto inventivo, já que está no espaço do entre, ou seja, na fronteira da língua, do que pode ou não ser dito. Ao tomar a perspectiva de arquivo, proposta por Foucault (2007), que corresponde à lei do que pode ser pronunciado, é possível salientar que o testemunho (Agamben, 2008) difere dele por estar entre o dentro e fora do sistema de construção de frases possíveis, não garantindo a verdade dos fatos do enunciado presente no arquivo, porém, o seu aspecto de exterioridade.

Com base nesse fator, os testemunhos, tidos como discursos menores frente aos oficiais, podem tecer ações micropolíticas articuladas - a partir de premissas estabelecidas por Deleuze e Guattari (1997) - tanto aos movimentos e ao que está no plano de visibilidade (narrativa extensiva), quanto à velocidade e aos afetos (narrativa intensiva). Pelas pontuações sobre esses dois tipos de narrativa, afere-se que o corpo se escreve pelo aspecto tanto do espaço liso (que abriga os acontecimentos, forças) quanto do espaço estriado (configurado por propriedades). Salientam Deleuze e Guattari (1997: 163):

O espaço liso são as intensidades, os ventos e ruídos, as forças e as qualidades tácteis e sonoras, como no deserto, na estepe ou no gelo. Estalido do gelo e canto das areias. O que cobre o espaço estriado, ao contrário, é o céu como medida, e as qualidades visuais mensuráveis que derivam dele. 
Considerando o exposto, os testemunhos das pessoas em situação de rua, que surgem em razão das marcas da desfiliação social, podem auxiliar nas tentativas de escrita de uma história que abarque as minúcias dos enfretamentos, provocando debates sobre o que gera inquietação no mundo e movendo, assim, de acordo com Suely Rolnik (1995), o pensamento, posto que ele serve de ponte ao fazer com o que está na esfera sensível seja visto e dito. Conclui-se, portanto, que o trabalho intelectual aliado a uma ética também se mostra como luta política, ao passo que provoca diálogos, narrativas testemunhais que se dão pela produção da diferença em nível artesanal, pelas costuras errantes.

De acordo com Foucault (2009), ao longo dos séculos XVII e XVIII, as disciplinas se constituíram como formas de dominação e se caracterizaram como "anatomia política" e "mecânica do poder", em função de objetivar do corpo humano sua obediência e utilidade, a partir de uma coerção contínua que esquadrinhasse tempo, espaço e movimentos. Diferentemente da escravidão, da domesticidade, da vassalidade e do ascetismo e "disciplinas" do tipo monástico, as disciplinas aqui abordadas estão relacionadas à busca pela produção de corpos dóceis, ou seja, submissos e exercitados, que aumentem as forças de utilidade econômica e diminuam as de utilidade política, a fim de obter expansão das aptidões e da sujeição. Atenta às minúcias, a via disciplinar se define como uma política do detalhe, presente não só em lugares fechados, uma vez que organiza um espaço analítico e difuso, infiltrando-se em arquiteturas, na classificação dos corpos, no monitoramento dos gestos. Ao mesmo tempo em que fixa os indivíduos, permite sua circulação, com base em princípios de organização e controle.

Lemos, Cardoso Júnior e Alvarez (2013) sublinham que, na sociedade disciplinar, em virtude da mobilidade e dinamismo dos arranjos que favorecem as articulações em rede, é a disciplina como um mecanismo em meio aberto que se apresenta de forma generalizada, em detrimento do modelo de instituição asilar que funciona como exceção.

Então, a sociedade disciplinar se organiza de acordo com a contiguidade de vários espaços disciplinares, onde funções, embora diferentes entre si quanto a seu objetivo, se interconectam no sentido de que obedecem ao mesmo diagrama ou organização. Dessa forma, o ideal da sociedade disciplinar é maximizar o exercício da função em cada espaço para que as várias funções disciplinares se encadeiem sem lacunas. A sociedade disciplinar também precisa aumentar os espaços disciplinares, a fim de que o deslocamento dos indivíduos entre os vários espaços não interrompa a continuidade da normalização. (Lemos; Cardoso Júnior; Alvarez, 2013: 102). 
Importante ressaltar que na disciplina há também incitação, produção, para além de uma noção de controle repressivo, em função da fluidez das forças que a compõem e dos jogos de saber e poder dos quais ela faz parte. Dessa maneira, é oportuno ter em vista a multiplicidade de conexões que são operadas no campo disciplinar, a fim de abarcar seus paradoxos e a especificidade dos contextos.

Em virtude de o corpo estar inserido em uma ampla rede parece bastante interessante, além da disciplina, as definições de biopolítica e biopoder, propostas por Foucault (1999), a fim de se obter uma compreensão diferenciada acerca das relações entre corpo e poder. A biopolítica, concebida como uma tecnologia do biopoder está voltada para a população, aos seus fenômenos aleatórios e de conjunto, com o objetivo de manter a sociedade em equilíbrio por meio de mecanismos de regulamentação. Assim, ao focar na população que é composta por multiplicidades de variadas ordens, como biológica, científica e política, a racionalidade biopolítica, ao mesmo tempo em que se infiltra pelos diversos campos para controlar os corpos, tentando mantê-los dentro de estados globais de estabilidade e regularidade, também os estimula a buscar por suas potências, as quais possam garantir o aprimoramento da vida.

Vista, portanto, como uma tecnologia do corpo, tal qual a disciplina, diferencia-se desta última por se voltar aos corpos em aspecto coletivo, enquanto os mecanismos disciplinares os tomam a partir de sua individualidade. No entanto, disciplina e biopolítica aparecem relacionadas à norma que por estas circula e opera simultaneamente ao deslizamento das existências e corpos nos entremeios das tramas de invenção e resistências às normas. Afirma Foucault (1999: 302);

A norma é o que pode tanto se aplicar a um corpo que se quer disciplinar quanto a uma população que se quer regulamentar. A sociedade de normalização não é, pois, nessas condições, uma espécie de sociedade disciplinar generalizada cujas instituições disciplinares teriam se alastrado e finalmente recoberto todo o espaço - essa não é, acho eu, senão uma primeira interpretação, e insuficientemente, da ideia de sociedade de normalização. A sociedade de normalização é uma sociedade em que se cruzam, conforme uma articulação ortogonal, a norma da disciplina e a norma da regulamentação.

Partindo do exposto, nota-se que tanto os cuidados do corpo como a gestão da vida são atravessados pelo biopoder, o qual busca se efetivar por meio de aspectos de normalização. Em função de a sociedade contemporânea, permeada pela medicalização constante, estar cada vez mais voltada para o 
enquadramento de pessoas como "anormais", são vistas inúmeras estratégias biopolíticas que legitimam práticas higienistas e racistas. Foucault (1999) sublinha que o racismo procura distinguir os que devem viver dos que devem morrer, trazendo também a noção da relação biológica, a qual justifica a extinção do outro em nome da sociedade, de sua defesa.

A morte do outro não é simplesmente a minha vida, na medida em que seria minha segurança pessoal; a morte do outro, a morte da raça ruim, da raça inferior (ou do degenerado, ou do anormal), é o que vai deixar a vida em geral mais sadia; mais sadia e mais pura. [...] Portanto, relação não militar, guerreira ou política, mas relação biológica. E, se esse mecanismo pode atuar é porque os inimigos que se trata de suprimir não são os adversários no sentido político do termo; são os perigos, externos ou internos, em relação à população e para a população. Em outras palavras, tirar a vida, o imperativo da morte, só é possível no sistema de biopoder, se tende não à vitória sobre os adversários políticos, mas à eliminação do perigo biológico e ao fortalecimento, diretamente ligado a essa eliminação, da própria espécie ou raça. A raça, o racismo, é a condição de aceitabilidade de tirar a vida numa sociedade de normalização. (Foucault, 1999: 305-306).

Nesse sentido, é importante perceber como os discursos segregacionistas podem estar articulados a diferentes pontos da sociedade, os quais os fazem funcionar também fora de uma lógica meramente de Estado. Tal racionalidade pode ser vista com a legitimação da violência pautada na crescente expectativa de pessoas que querem se afastar das ditas "impurezas" sociais, tais como a pobreza, que, estigmatizada pela virtualidade criminosa, é tida como um obstáculo ao desenvolvimento dos centros urbanos.

\section{Considerações finais}

Para Foucault (2012), emaranhadas as estratégias de controle da sociedade, que vão além das desempenhadas pelo Estado, estão as práticas de governo de condutas, as quais podem ser mais bem entendidas a partir da noção de governamentalidade. Esta se refere às formas variadas de governar presentes desde o século XVIII, permitindo a sobrevivência do Estado por meio de técnicas de governo que se dão em seu exterior e interior.

De acordo com o Vocabulário de Foucault (Castro, 2009), há dois modos de entendimento da governamentalidade que estão em conformidade com os dois eixos da noção foucaultiana de governo (dos outros e de si): 1) governamentalidade 
política, que se debruça sobre a racionalidade, técnicas e modos de instrumentalização do governo, tendo como foco a população; 2) o encontro das técnicas de dominação sobre os outros e as técnicas de si, que, por sua vez, possibilita a ocorrência de processos de resistência. Nesse sentido, a análise da governamentalidade envolve as artes de governar, as quais comportam:

[o] estudo do governo de si (ética), o governo dos outros (as formas políticas da governamentalidade) e as relações entre o governo de si e o governo dos outros. Nesse campo estariam incluídos: o cuidado de si, as diferentes formas de ascese (antiga, cristã), o poder pastoral (a confissão, a direção espiritual), as disciplinas, a biopolítica, a polícia, a razão de Estado, o liberalismo. (Castro, 2009: 191).

Segundo Foucault (2012), em virtude de a arte de governar ter, inicialmente, buscado amparo no modo de operar da soberania (voltada para a questão do território), e por não ter ignorado o modelo de família, ficou, a princípio, sem constituir um espaço próprio, sofrendo, assim, uma espécie de bloqueio pela noção de economia (relativa no momento apenas à família e sua casa). Contudo, após a eclosão da questão da população, a arte de governar pôde ser desbloqueada, com base no desenvolvimento da ciência do governo que levou à centralização da economia - antes concentrada na família - no que foi chamado pelo autor de nível de realidade caracterizado como econômico, com base no qual as particularidades da população passaram a ter ênfase em outra esfera, não restritas ao campo da soberania. Desse modo, a economia no século XVIII passou a ocupar outro lugar, diferentemente daquele que ocupava no século XVI, quando era vista apenas como uma forma de governo (arte de governar a família), junto aos outros dois tipos: da moral (governo de si mesmo) e da política (ciência de bem governar o Estado). A governamentalidade, para o autor, portanto, diz respeito ao Estado de governo que foca na questão populacional e faz uso dos instrumentos fornecidos pelo saber econômico, controlando por meio dos dispositivos de segurança a sociedade.

Em meio às diferentes estratégias de controle do espaço, do corpo e da população, é importante sublinhar as brechas que permitem a manifestação de resistências, as quais se dão por meio de tensões que incitam as lutas na busca por transformações. $\mathrm{O}$ ato de resistir, que não se restringe a ser contrário a uma determinada força, está implicado na produção da dobra, assim caracterizada por Deleuze (1992, p. 127), com base em uma analítica foucaultiana: 
Trata-se de "duplicar" a relação de forças, de uma relação consigo que nos permita resistir, furtar-nos, fazer a vida ou a morte voltarem-se contra o poder. Foi o que os gregos inventaram, segundo Foucault. Não se trata mais de formas determinadas, como no saber, nem de regras coercitivas, como no poder: trata-se de regras facultativas que produzem a existência como obra de arte, regras ao mesmo tempo éticas e estéticas que constituem modos de existência ou estilos de vida.

Por essa perspectiva, o corpo em situação de rua, pensado também pelo prisma do exercício de resistência, mostra suas potências de luta que comprovam o desvio das práticas de normalização, bem como o enfrentamento de situações adversas, deixando o registro da violência vivida em si mesmo e demarcando, a partir das marcas corporais, um tipo de existência feroz. Não à toa, cicatrizes de cortes e marcas de bala denunciam algo além do ato violento: o da sobrevivência. E não à toa também o andar fora do tempo padronizado da cidade sugere práticas de liberdade que vão além da marginalização dos "anormais", as quais apontam, segundo Foucault (2004), para condutas realizadas com base em um trabalho de si que o sujeito realiza sobre si mesmo.

Assim, observa-se que, embora as capturas sejam extensas, o paradoxo se mostra presente, já que o resistir pelas brechas se configura não apenas pela negatividade, ou seja, como uma oposição ao que é imposto, mas também como forma de invenção, de criação de modos de vida. Por fim, com base nas lógicas disciplinares e biopolíticas, assim como no desenvolvimento do conceito de governamentalidade, é possível redimensionar a reflexão a propósito dos dispositivos de normalização das condutas, do domínio dos corpos e de suas respectivas relações com a questão da população em situação de rua e com a sua produção de resistências.

\section{Referências}

AGAMBEN, Giorgio. Profanações. São Paulo: Boitempo, 2007. O que resta de Auschwitz. São Paulo: Boitempo, 2008. . Homo Sacer: O Poder Soberano e a Vida Nua I. Belo Horizonte: Editora UFMG, 2010.

BAUMAN, Zygmunt. Globalização: as consequências humanas. Rio de Janeiro: Jorge Zahar, 1999. Confiança e medo na cidade. Rio de Janeiro: Jorge Zahar, 2009.

BEAUJOU-GARNIER, Jacqueline. Geografia urbana. Lisboa: Fundação Calouste Gulbenkian, 1997. 
CASTEL, Robert. A gestão dos riscos: da antipsiquiatria à pós-psicanálise. Rio de Janeiro: Francisco Alves, 1987.

As armadilhas da exclusão. In: CASTEL, Robert; WANDERLEY, Luiz Eduardo; BELFIORE-WANDERLEY, Mariangela (Org.). Desigualdade e a questão social. São Paulo: EDUC, 1997. pp. 17-50.

As metamorfoses da questão social: uma crônica do salário. Rio de Janeiro: Vozes, 2010.

. A discriminação negativa: cidadãos ou autóctones? Petrópolis: Vozes, 2011.

CASTRO, Edgardo. Vocabulário Foucault: um percurso pelos seus temas, conceitos e autores. Belo Horizonte: Autêntica, 2009.

O governo da vida. Ecopolítica, v. 3, pp. 69-98, 2012.

CÉSAR, Janaína Mariano; SILVA, Fabio Hebert da; BICALHO, Pedro Paulo Gastalho de. O lugar do quantitativo na pesquisa cartográfica. Fractal, v. 25, n. 2, pp. 357-372, 2013. COSTA, Luis Artur; ANGELI, Andréa do Amparo Carotta de; FONSECA, Tania Mara Galli. Cartografar. In: FONSECA, Tania Mara Galli; NASCIMENTO, Maria Lívia do; MARASCHIN, Cleci (Org.). Pesquisar na diferença: um abecedário. Porto Alegre: Sulina, 2012. pp. 45-48.

DELEUZE, Gilles. Diferença e Repetição. Tradução Luis Orlandi e Roberto Machado. Rio de Janeiro: Graal, 1988. . Conversações, 1970 - 1972. Rio de Janeiro: Editora 34, 1992. ; GUATARRI, Félix. Mil platôs: capitalismo e esquizofrenia (vol. 1). Rio de Janeiro: Editora 34, 1995a.

. Mil platôs: capitalismo e esquizofrenia (vol. 2). Rio de Janeiro: Editora 34, 1995b. . Mil platôs: capitalismo e esquizofrenia (vol. 7). Rio de Janeiro: Editora 34, 1997.

FOUCAULT, Michel. Microfísica do poder. Rio de Janeiro: Edições Graal, 1979.

. Em defesa da sociedade. Curso no Collège de France (1975-1976). São Paulo: Martins Fontes, 1999.

. A Vida dos Homens Infames. In: MOTA, Manuel Barros da (Org.). Michel Foucault: Ética, estratégia, poder-saber. Rio de Janeiro: Forense Universitária, 2003. . A ética do cuidado de si como prática de liberdade. In: MOTTA, Manuel Barros da (Org.). Michel Foucault: ética, sexualidade e política. Rio de Janeiro: Forense Universitária, 2004. pp. 264-287 (Ditos e escritos V).

FRANGELLA, Simone Miziara. Corpos urbanos errantes: uma etnografia da corporalidade de moradores de rua em São Paulo. 2004. Tese (Doutorado) - Universidade Estadual de Campinas, Campinas, SP, Brasil, 2004.

GALINDO, Dolores; MARTINS, Mário; RODRIGUES, Renata Vilela. Jogos de armar: narrativas como modo de articulação de múltiplas fontes no cotidiano da pesquisa. In: SPINK, Mary Jane Paris; BRIGAGÃO, Jacqueline Isaac Machado; NASCIMENTO, 
Vanda Lúcia Vitoriano do Nascimento; CORDEIRO, Mariana Prioli (Org.). A produção de informação na pesquisa social: compartilhando ferramentas. Rio de janeiro: Centro Edelstein de Pesquisas Sociais, 2014.

GALLO, Sílvio. Conhecimento, transversalidade e Educação. Para além da interdisciplinaridade. Revista Impulso, Piracicaba: UNIMEP, v. 10, n. 21, pp. 115-133, 1997.

GOFFMAN, Erving. Estigma: notas sobre a manipulação da identidade deteriorada. Rio de Janeiro: Zahar, 1982.

GUATTARI, Félix; ROLNIK, Suely. Micropolítica: cartografias do desejo. Petrópolis: Vozes, 2011.

JACQUES, Paola Berenstein. Corpografias urbanas. São Paulo: Arquitextos/Vitruvius, 2008. Disponível em: <http://www.vitruvius.com.br/revistas/read/arquitex-

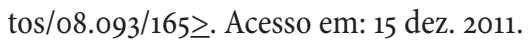

JUSTO, José Sterza. Errâncias e errantes: um estudo sobre os andarilhos de estrada. In: JUSTO, José Sterza; SAGAWA, Roberto Yutaka (Org.). Rumos do saber psicológico. São Paulo: Arte \& Ciência, 1998. pp. 125-139.

; NASCIMENTO, Eurípedes Costa do. Errância e delírio em andarilhos de estrada. Psicologia: Reflexão e Crítica. pp.177-187, 2005.

LEMOS, Flávia Cristina Silveira. Problematizar. In: FONSECA, Tania Mara Galli; NASCIMENTO, Maria Lívia do; MARASCHIN, Cleci (Org.). Pesquisar na diferença: um abecedário. Porto Alegre: Sulina, 2012. pp. 191-193.

; CARDOSO JÚNIOR, Hélio Rebello. Genealogia em Foucault: uma trajetória. Psicologia e Sociedade. Florianópolis, v. 21, n. 3, 2009.

; CARDOSO JÚNIOR, Hélio Rebello; ALVAREZ, Marcos César. Instituições, confinamento e relações de poder: questões metodológicas no pensamento de Michel Foucault. Psicologia \& Sociedade. v. 26, pp. 100-106, 2013.

; CHAVES, Silvia Nogueira; PRADO FILHO, Kleber. In: LEMOS, Flávia Cristina

Silveira et al. (Org.). Transversalizando no ensino, na pesquisa e na extensão. Curitiba: CRV, 2012. pp. 21-31.

; LOBO, Lilia Ferreira Lobo; RODRIGUES, Heliana de Barros Conde. In: LEMOS, Flávia Cristina Silveira et al. (Org.). Transversalizando no ensino, na pesquisa e na extensão. Curitiba: CRV, 2012. pp. 45-53.

MAGNI, Claudia Turra. Nomadismo urbano: uma etnografia sobre moradores de rua de Porto Alegre. Santa Cruz do Sul: EDUNISC, 2006.

ORTEGA, Francisco. Amizade e estética da existência em Foucault. Rio de Janeiro: Graal, 1999.

Da ascese à bio-ascese ou do corpo submetido à submissão ao corpo. In: PAGOT, Angela Maria. O louco, a rua, a comunidade: as relações da cidade com a loucura em situação de rua. Rio de Janeiro: Fiocruz, 2012. 
PASSETTI, Edson. Para o neoliberalismo a democracia começa no mercado, entrevista de Edson Passetti a Rafael Evangelista. Com Ciência. v. 67, 2005.

. Governamentalidade e violências. Currículo sem Fronteiras. v. 11, n.1, pp. 42-53, 2011.

REVEL, Judith. Dicionário de Foucault. Rio de Janeiro: Forense Universitária, 2011.

RODRIGUES, Ana Cabral; BAPTISTA, Luis Antônio dos Santos. Cidades-imagem: afirmações e enfrentamentos às políticas da subjetividade. Psicologia \& Sociedade. v. 22, n.3, pp. 422-429, 2010.

ROLNIK, Raquel; KLINK, Jeroen. Crescimento econômico e desenvolvimento urbano: por que nossas cidades continuam tão precárias? Novos Estudos. v. 89, pp. 89-109, 2011.

ROLNIK, Suely. Ninguém é deleuziano. Entrevista a Lira Neto e Silvio Gadelha. O Povo. Caderno Sábado. Fortaleza, 1995.

VIRILIO, Paul. O espaço crítico. Rio de Janeiro: Editora 34, 1993.

ZAMBENEDETTI, Gustavo; SILVA, Rosane Azevedo Neves. Cartografia e genealogia: aproximações possíveis para a pesquisa em psicologia social. Psicologia \& Sociedade. v. 23 n. 3, pp. 454-463, 2011.

ZOURABICHVILI, François. O vocabulário de Deleuze. Rio de Janeiro: Relume Dumará, 2009.

Recebido em 03/04/2015

Aprovado em 03/02/2016

\section{Como citar este artigo:}

SILVA, Daiane Gasparetto da; LEMOS, Flávia Cristina Silveira; GALINDO, Dolores. Corpos em situação de rua: entre práticas de normalização e resistência. Contemporânea Revista de Sociologia da UFSCar, v. 6, n. 2, jul.-dez. 2016, pp. 467-484. 